\title{
Quality Improvement Training Framework Adoption at Katutura Hospital in Windhoek Namibia
}

\author{
Bernardus Franco Maseke, Bongani Nyathi \\ Faculty of Economics and Management Science, University of Namibia, Keetmanshoop, Namibia \\ Email: fmaseke@gmail.com, bonganiboboe@gmail.com
}

How to cite this paper: Maseke, B.F. and Nyathi, B. (2021) Quality Improvement Training Framework Adoption at Katutura Hospital in Windhoek Namibia. Open Access Library Journal, 8: e6945.

https://doi.org/10.4236/oalib.1106945

Received: October 25, 2020

Accepted: January 26, 2021

Published: January 29, 2021

Copyright $\odot 2021$ by author(s) and Open Access Library Inc.

This work is licensed under the Creative Commons Attribution International License (CC BY 4.0).

http://creativecommons.org/licenses/by/4.0/ (c) (i) Open Access

\begin{abstract}
In Namibia, most health care facilities have not been yielding good results in response to patients' health care needs. Health care systems are becoming more complex with paradoxical challenges resulting into inefficiencies due to ever increasing science and knowledge in medicine, which makes it difficult to internalise and understand, as well as to implement certain procedures. The study explored and found that research indicates that total quality management (TQM) and continual quality improvement (CQI) principles can be applied to strengthen a health system to improve its quality. This could be particularly useful in Namibia where people demand basic services and the health service users raise their issues with the Ministry of Health and Social Services (MoHSS). It becomes essential to ascertain the extent to which health care facilities have responded to this call. Against this background, it is important to analyze the responses to QI and QA and how it could be used to develop a framework for quality health care delivery at the health care facilities in Namibia. The main focus of this paper is to identify quality improvement aspects at Katutura Hospital and to develop a quality improvement training framework to empower and equip health professionals with the right knowledge, skills, aptitudes, and behaviours to apply the methods and techniques with the purpose of improving customer service.
\end{abstract}

\section{Subject Areas}

Economics

\section{Keywords}

Customer Service, Continual Quality Improvement, Total Quality

Management, Training Needs Analysis, Health Professionals 


\section{Introduction}

The Ministry of Health and Social Services has as its mandate, the custodian of health and social services, the Ministry of Health and Social Services has the mandate to oversee, provide and regulate public, private and non-governmental sectors in the provision of quality health and social services, ensuring equity, accessibility, affordability and sustainability. Quality improvement (QI) training refers to any activity that explicitly aims at teaching health professionals about methods that could be applied to analyze and improve quality health care (The Health Foundation, 2012) [1]. A QI training programme would equip and empower health professionals with skills and competencies to improve health care delivery and meet the increasing demands of the patients.

As this is echoed by the facts that the health professionals are facing in their quest for quality health care delivery. In Namibia, most health care facilities have not been yielding good results in response to patients' health care needs (The Health Foundation, 2012) [1]. Health care systems are becoming more complex with paradoxical challenges resulting into inefficiencies due to ever increasing science and knowledge in medicine, which makes it difficult to internalise and understand, as well as to implement certain procedures (Casali et al., 2013) [2].

The study by (Casali et al., 2013) [2] explored and found that research indicates that TQM and continual quality improvement (CQI) principles can be applied to strengthen a health system to improve its quality. This could be particularly useful in Namibia where people demand basic services and the health service users raise their issues with the Ministry of Health and Social Services (MoHSS). It becomes essential to ascertain the extent to which health care facilities have responded to this call. Against this background, it is important to analyze the responses to QI and QA and how it could be used to develop a framework for quality health care delivery at the health care facilities in $\mathrm{Na}$ mibia. The main focus of this paper is to aim to develop a training programme to empower and equip health professionals with the right knowledge, skills, aptitudes, and behaviours to apply the methods and techniques with the purpose of improving customer service. The background of the study steams from poor customer service delivery experience over the years at Katutura hospital and little to no intervention from authorities to improve the situation.

\section{Literature Review}

The purpose of a literature review is to educate the reader about topic area and to understand the literature before shaping an argument or justification. Instructional Theory for Skill Development The theory for fostering skill development outcomes, as proposed by Romiszowski (2009) [3], can be used for fostering all types of skills. Romiszowski defines skill as "the capacity to perform a given type of task or activity with a given degree of effectiveness, efficiency, speed or other measures of quantity or quality". He distinguishes between intellectual skills (that involve the mind), motor, sensorimotor, or psychomotor skills (that in- 
volve the body), personal skills (that involve emotions), and interpersonal skills (that involve interacting with others). Skill is distinct from knowledge, in that it develops with experience and practice, whereas knowledge is something that an individual either has or does not have.

Health improvement planning models exist to support strategic management of health improvement efforts and to guide program administrators in taking a comprehensive approach to health promotion planning from problem identification to program evaluation and diffusion. Traditional academics for instance Steuart (1969) [4], mentioned that the importance of health educators including rigorous evaluations in programs designed to promote health and prevent illness has been noted in the literature for many years. Present conceptual and technical design issues and options.

In Namibia, a quality improvement training programme seems to be the best option to address quality health care issues; more especially when the Katutura Hospital has planned a new direction in quality improvement and quality assurance to promote quality health care delivery. Meyer and Van Niekerk (2008) [5] developed a quality improvement training with phases for health professionals to give better results and customer service. Those five phases were situational analysis, conceptual framework, developing of the training programme, development of the guidelines for the implementation, and evaluation of training programme. According to the National Leadership and Innovation Agency for Health (NLIAH) (2008) [6], most health systems face challenges in providing high quality patient care to meet health care needs.

According to Agency for Research and Quality (2005), research has even emphasised that health professionals need to be constantly involved in acquiring knowledge, skills, and aptitudes that would enable them to apply new methods to providing quality health care that meets the health needs of their patients. Although health care facilities strive to achieve quality, there seems to be inadequate quality improvement programmes that could guide and prepare health professionals in their quest to provide quality health care delivery.

\section{Research Methodology}

\subsection{Introduction}

In this part of the paper, the various proposed tools needed to gather the relevant information that will be been listed and the methodology for analyzing the data will thus be explained. The paper is divided into the following sections. Research design, detailed population from which the study will contain findings, sampling technique used, research instrument and measures used to collect data.

\subsection{Research Design}

The proposed research design is comparative since the data collected from different investigations are compared. The qualitative approach is about what was 
said or done. In this respect, different procedures and data collection instruments have to be employed. These principally include interview, observation, reading and transcribing to what Katutura Hospital required for better service. Different methods for more concrete information were used on random groups to collect data and ensure its effectiveness.

\subsection{Population of Study}

A population is the total collections of elements about which inference is to be made (Cooper and Schindler, 2006) [7]. A research frame refers to all elements which information may be gleaned to solve a research problem. The population for this study covered the health professionals from all departments of the hospital. The population includes a portion the heads of departments, nurses, health administration and the volunteers at the hospital. The total size of the population was 618 staff members.

\subsection{Data Collection}

Observation tools for collecting primary data where recommended for the composite of qualitative research designs. Secondary data collection is recommended for exploratory analysis using the qualitative methods of data collection (Saunders et al., 2003). Before the acquiring of data in terms of the face to face respondents permission was requested from the Ministry of Health and Social Services official representatives to undertake the interviews. The data was collected by use of observations and interviews. Observations were used to collect qualitative data not revealed and obtainable from participants and interviews were used to collect in-depth qualitative data from participants. The top management members completed a self-administered checklist to confirm the approaches in relation to quality health care delivery at Katutura Hospital. The right to privacy of respondents was taken into consideration. This is in the sense that respondents had the right to choose to disclose their identity or remain anonymous.

Adopted from Meyer and Van Niekerk (2008) [5] the implementation of the five phases is enabled the structured collection of data. The modified such as situational analysis; conceptual framework; developing of the training programme; development of the guidelines for the implementation; and evaluation of training programme is briefly described as follow:

- Phase 1: Situation analysis sought to explore and describe the experiences of top managers and health professionals about quality improvement and quality assurance at the health facilities with the view of improving quality health care delivery.

- Phase 2: The conceptual framework of this study was based on the practice orientated theory of Dickoff (1968) that assisted with explaining the concepts used in developing the quality improvement training programme for health professionals at the health facilities. 
- Phase 3: Process of developing the training program.

- Phase 4: This phase of the study focused on developing the guidelines for implementing the training programme.

- Phase 5: The last phase five focused on the evaluation of the quality improvement training programme.

\section{Data Findings and Discussions}

The findings from using the phases have revealed that some ambiguities in the availability of policies and guidelines, leadership to facilitate care delivery, health system infrastructure, patient safety, as well as research and information to facilitate quality health delivery for improved quality. However, the adoption will thus facilitate the following thus achieving the major goal of improving Katutura Hospital. Some of the positive findings that where found are:

- Equipping health professionals on policies and guidelines on QI to facilitate quality health care.

- Empower health professionals on management and utilisation of resources to enhance quality health care delivery.

- Empower health professionals on mechanisms to improve interpersonal relationships among health professionals and between clients to enhance quality health care delivery.

The adoption of the education program showed that the advancement of technology can be administered to health workers. This in the sense brings about more confidence to the hospital staff to approach patients with less ease. The education program can equip the hospital at a whole for any unforeseen out breaks. The adoption can thus be weighted as the program can also carry limitations that involve financial constraints. The hospital might need to facilitate funds and time for the training to ensure that the program is a success. Language barriers can distort or give misinterpretations for instance using English to communicate might have contributed to barriers for people to express their opinions freely.

There might be some exclusion of quality aspects in other health care environments; these quality aspects could be useful for comparing similarities and differences among different settings. Any change in methods, processes, and structures might also influence data omissions.

\section{Recommendations}

In order to address the critical challenges and constraints hampering quality health care delivery, the management should establish mechanisms to streamline the policies and guidelines. This is in that sense that Katutura hospital should always have a proactive procedure to do overall programs to monitor and evaluate service delivery. Therefore, the researcher recommends that policies and guidelines should form part of the quality improvement training programme in order to understand the principles and standards that are meant to enhance 
quality health care delivery at the health care facilities.

In order to complete the loop of quality health care delivery and improve the health care services, an enquiry into the perceptions of patients' satisfaction should be conducted to compare the findings and generate data for adequate planning and decision-making about patient safety. Patients revealed that they wait on queues for several hours every day before they can be examined by a medical practitioner. To remedy the queues hospitals can enable that there is a practitioner on duty to speed the process up. The practitioner can rate the patients that need instant attention to be treated first and discharged thus enable the process to be speeded up.

\section{Conclusions}

In conclusion, it can be highlighted that the training programme contributes to the body of knowledge by seeking to facilitate the successful implementation of the training programme at the health care facilities in the MOHSS including Katutura Hospital. An adoption quality improvement training programme was the primary objective of this study and the main contribution to the field of quality management and improvement in health care. The study formulated the guidelines for the implementation and evaluation of the training programme. The recommendations thus will also help conclude in the justification that remedies need to be set in place to create better customer service.

The significance of the study was also to ensure that better medical services are provided to the community and various stakeholders through the effective implementation and evaluation of training programmes. In addition, government financial and other resources can efficiently be used to serve more clients in a shorter period of time thus reducing the time spent by clients at heath centres such as Katutura hospital.

\section{Conflicts of Interest}

The authors declare no conflicts of interest regarding the publication of this paper.

\section{References}

[1] The Health Foundation (2012) Evidence Scan: Quality Improvement Training for Healthcare Professionals.

[2] Casali, M., Marraro, G., Spada, C. and Steffano, G. (2013) Current Topics. In: Healthcare Safety and Accountability. http://www.healthcsa.org

[3] Romiszowski, A. (2009) Fostering Skill Development Outcomes. In: Reigeluth, C.M., Eds., Instructional-Design Theories and Model, Routledge, New York, 199-224.

[4] Steuart, G.W. (1969) Planning and Evaluation in Health Education. International Journal of Health Education, 12, 65-67.

[5] Meyer, S. and Van Niekerk, S. (2008) Nurse Educator in Practice. Juta \& Co Ltd., Cape Town. 
[6] National Leadership and Innovation Agency for Health (2008) Engaging Clinicians in a Quality Agenda. Resource Paper.

[7] Cooper, D.R. and Schindler, P.S. (2006) Business Research Methods. 9th Edition, McGraw-Hill, USA. 